\title{
Is Paradoxical Pain Induced by Sustained Opioid Exposure an Underlying Mechanism of Opioid Antinociceptive Tolerance?
}

\author{
Tamara King Michael H. Ossipov Todd W. Vanderah Frank Porreca \\ Josephine Lai
}

Department of Pharmacology, University of Arizona Health Sciences Center, Tucson, Ariz., USA

\author{
Key Words \\ Central sensitization • Cholecystokinin · Hyperalgesia • \\ Descending pain facilitation - Dynorphin - Rostral \\ ventromedial medulla
}

\begin{abstract}
Opiates are the primary treatment for pain management in cancer patients reporting moderate to severe pain, and are being increasingly used for non-cancer chronic pain. However, prolonged administration of opiates is associated with significant problems including the development of antinociceptive tolerance, wherein higher doses of the drug are required over time to elicit the same amount of analgesia. High doses of opiates result in serious side effects such as constipation, nausea, vomiting, dizziness, somnolence, and impairment of mental alertness. In addition, sustained exposure to morphine has been shown to result in paradoxical pain in regions unaffected by the initial pain complaint, and which may also result in dose escalation, i.e. 'analgesic tolerance'. A concept that has been gaining considerable experimental validation is that prolonged use of opioids elicits paradoxical, abnormal pain. This enhanced pain state requires additional opioids to maintain a constant level of antinociception, and consequently may be interpreted as antinociceptive tolerance. Many substances have been shown to block or reverse antinociceptive tolerance. A non-inclusive list of
\end{abstract}

examples of substances reported to block or reverse opioid antinociceptive tolerance include: substance $\mathrm{P}$ receptor (NK-1) antagonists, calcitonin gene-related peptide (CGRP) receptor antagonists, nitric oxide (NO) synthase inhibitors, calcium channel blockers, cyclooxygenase (COX) inhibitors, protein kinase $\mathrm{C}$ inhibitors, competitive and non-competitive antagonists of the NMDA (Nmethyl- $D$-aspartate) receptor, AMPA (alpha-amino-3hydroxy-5-methyl-4 isoxazolepropionic acid) antagonists, anti-dynorphin antiserum, and cholecystokinin (CCK) receptor antagonists. Without exception, these substances are also antagonists of pain-enhancing agents. Prolonged opiate administration indeed induces upregulation of substance $\mathrm{P}(\mathrm{SP})$ and calcitonin gene-related peptide (CGRP) within sensory fibers in vivo, and this is accompanied by an enhanced release of excitatory neurotransmitters and neuropeptides from primary afferent fibers upon stimulation. The enhanced evoked release of neuropeptides is correlated with the onset of abnormal pain states and opioid antinociceptive tolerance. Importantly, the descending pain modulatory pathway from the brainstem rostral ventromedial medulla (RVM) via the dorsolateral funiculus (DLF) is critical for maintaining the changes observed in the spinal cord, abnormal pain states and antinociceptive tolerance, because animals with lesion of the DLF did not show enhanced evoked neuropeptide release, or develop abnormal pain or antinociceptive tolerance upon sustained exposure to opiates. 
Microinjection of either lidocaine or a CCK antagonist into the RVM blocked both thermal and touch hypersensitivity as well as antinociceptive tolerance. Thus, prolonged opioid exposure enhances a descending pain facilitatory pathway from the RVM that is mediated at least in part by CCK activity and is essential for the maintenance of antinociceptive tolerance.

\section{Introduction}

Opiate analgesics, such as morphine and fentanyl, are the mainstay of pain management in conditions ranging from acute pain, postoperative pain to chronic pain including cancer pain, and are used as substitution treatment for opioid dependence $[1,2]$. These clinical uses of opiates often require opiate treatment for extended periods. However, the use of opioid analgesics for the treatment of many chronic pain states is often offset by the development of tolerance. Antinociceptive tolerance is defined as the decrease in analgesic activity of a drug after a previous exposure to the same or a similar drug [3-6]. Thus, higher doses of the drug are required to elicit the same amount of pain relief. Opioid analgesic tolerance is well recognized experimentally and clinically, and can occur over a period of days to weeks [4-6]. Clinically, the need for increasing doses of opioids in cases of chronic pain is well documented and is a major obstacle to providing adequate pain relief over a long period of time [4, 5, 7].

In animal studies, antinociceptive tolerance is defined as a rightward shift in the antinociceptive effect of morphine challenge in nociceptive assays. This rightward shift in the dose response curve has been demonstrated following repeated daily systemic injections of morphine to mice or rats as well as following repeated intrathecal injections of morphine in rats [8-10]. Prolonged exposure to subdermal slow-release morphine pellets likewise produces a significant shift to the right in the dose-effect curve for subsequent morphine challenge administered either spinally (intrathecally) or supraspinally (intracerebroventricularly) $[11,12]$. In addition, prolonged exposure to spinal administration of the mu opioid receptor agonist DAMGO through osmotic mini-pumps resulted in decreased antinociceptive potency and efficacy of spinal opioids [13]. Despite intensive research documenting the occurrence of antinociceptive tolerance, the mechanism underlying this phenomenon remains a subject of much debate. This review will give an overview of changes observed at the cellular as well as the systemic level following prolonged opiate exposure.

\section{Signaling Changes as a Mechanism of Opiate Antinociceptive Tolerance}

\section{Homologous Desensitization and Down-Regulation}

Opiate drugs and endogenous opioid neuropeptides produce their physiological effects through the activation of three structurally distinct receptors that are members of the superfamily of G protein-coupled receptors (GPCR). The mu opioid receptor (MOR), the delta opioid receptor (DOR) and the kappa opioid receptor (KOR) are encoded by different genes and are well defined pharmacologically [14]. The acute activation of opioid receptors results in decrease in neuronal excitability and neurotransmission by the activation of a class of inwardly rectifying potassium channels, and the inhibition of certain voltage-sensitive calcium channels (for review, see $[15,16]$ ). In nociceptive transmission, for example, the activation of opioid receptors in the primary afferent $C$ fibers results in hyperpolarization of these neurons, decreased firing, inhibited release of excitatory neurotransmitters including glutamate [17] and substance P $[18,19]$ from the central termini of these afferent fibers in the dorsal horn of the spinal cord. Opioid receptors are also expressed in post-synaptic, intrinsic neurons within the spinal cord [20-22]. Thus, activation of these receptors by spinal administration of opioid agonists may elicit antinociception by pre-synaptic modulation of the activity of primary afferent fibers, or by post-synaptic influence on other spinal neurons.

One proposed mechanism of antinociceptive tolerance after sustained opioid exposure is through agonistinduced receptor desensitization and downregulation of functional receptors present in target neurons [23, 24]. A decrease in functional, cell surface receptors as a result of prolonged agonist exposure is a characteristic common to many GPCR that have been studied to date and as such, receptor desensitization and downregulation as a cellular mechanism of drug tolerance is widely accepted $[16,24]$. Like other members of the GPCR superfamily, prolonged agonist activation of opioid receptors results in receptor phosphorylation by $\mathrm{G}$ protein-coupled receptor kinases (GRKs), uncoupling of the receptors from $G$ proteinmediated intracellular signaling, and recruitment of betaarrestins [25-29]. Recruitment of beta-arrestin promotes the attachment of the $G$ protein-coupled receptors to clathrin-coated pits that subsequently undergo endocytosis (i.e. receptor internalization) via a dynamin-dependent mechanism [26, 28, 30]. Upon receptor internalization the receptors may be recycled to the membrane, leading to resensitization, or targeted for degradation, leading to receptor downregulation $[31,32]$. 
The role of beta-arrestins in opioid antinociceptive tolerance has been examined by antisense knockdown of beta-arrestin [33] and by studying transgenic mice that lack the gene that encodes beta-arrestin-2 [34-36]. Intrathecal administration of antisense for beta-arrestin was shown to decrease beta-arrestin mRNA by approximately $60 \%$ in vitro [33]. In vivo, spinal administration of these antisense oligonucleotides was shown to delay the development of tolerance to spinal morphine administration [33]. Administration of antisense for beta-arrestin was also reported to attenuate cold allodynia induced by nerve injury. The authors conclude that both morphine tolerance and neuropathic pain are mediated through receptor desensitization [33]. The relation between beta-arrestin and pro-nociceptive mechanisms within the spinal cord is unknown at this time. The beta-arrestin-2 null mutant mice showed increased sensitivity to the acute antinociceptive effects of morphine and did not develop antinociceptive tolerance [37]. The results from the betaarrestin knockdown and knockout studies have led to the proposal that beta-arrestin-mediated desensitization, and presumably receptor endocytosis, of opioid receptors is induced by morphine in vivo and is suggested to contribute directly to the development of physiological tolerance to opiates [37]. However, these results are not easily reconciled with findings of an inverse relationship between receptor endocytosis and opioid tolerance, as well as reports showing that prolonged administration of opiates fails to lead to opioid receptor downregulation as discussed below.

Numerous studies have reported that distinct opioid agonists, all of which produce antinociceptive tolerance, differ in their ability to modulate the number of surface accessible opioid receptors [38-42]. Several studies report that morphine fails to induce GRK-mediated phosphorylation of MOR, arrestin binding, or desensitization $[43,44]$. Morphine also fails to promote the internalization of MOR in cultured cells [38, 41], or in neurons [45, 46]. Consistent with the lack of MOR internalization following morphine exposure, many studies have also demonstrated a lack of downregulation of MOR in morphine tolerant animals (for review, see [16]). An alternative hypothesis proposes that agonists that induce internalization of opioid receptors may inhibit the development of anti-nociceptive tolerance by promoting the recycling of functional receptors to the cell surface, whereas agonists, such as morphine, that are poor activators of this trafficking process, are more likely to render the receptors in a desensitized state upon prolonged exposure [47]. In support of this hypothesis, it was found that enhancing mor- phine-induced receptor internalization attenuated the development of morphine tolerance in a cell culture model [47, 48]. Similarly, several studies in animal models also show that administration of agonists that promote receptor internalization, such as DAMGO, elicit less tolerance and dependence compared to those that fail to induce receptor internalization, such as morphine, when administered at equi-effective doses [49-51].

\section{Adenylyl Cyclase Superactivation}

Sustained opioid treatment in certain cultured cell models consistently results in a significant increase in the activation of adenylyl cyclase (AC), known as AC superactivation, along with a corresponding increase in the basal level of cAMP $[16,52,53]$. It has been shown that AC superactivation and the corresponding cAMP upregulation is due to a variety of factors including the cell models in question and the agonist used [16, 54-59]. The increase in basal cAMP has been proposed to be a cellular mechanism of opioid tolerance by requiring a greater extent of adenylyl cyclase inhibition through the opioid receptor/Gi-coupled pathway [16]. Recent research shows that there is selectivity in the interactions of G-protein alpha subunits upon differential agonist activation of the opioid receptor [60]. Some have argued that chronic opioid-induced AC superactivation could be due to a switch from receptor activation of inhibitory $\mathrm{G}$ proteins $(\mathrm{Gi})$ to enhanced receptor interaction with stimulatory proteins (Gs) upon chronic receptor activation [56, 57, 61]. Crain and Shen [61] proposed that the supersensitivity of mouse dorsal root ganglion neurons following chronic opioid treatment may be due to a shift of the opioid receptors' coupling from a predominantly Gi-mediated pathway to a higher incidence of Gs activation by the receptors. Thus, a switch in the receptor-G protein activity could account for the development of cellular tolerance as indicated by AC superactivation.

There are nine different $\mathrm{AC}$ isoenzymes described to date (for review, see [62, 63]). All AC isoforms, except for type I, are stimulated by $\mathrm{G}_{\mathrm{s}} \alpha$ and forskolin, and AC activity can be further modulated by several different secondary factors such as $\mathrm{G}_{\mathrm{i}} \alpha$ subunits, $\mathrm{G} \beta \gamma$ subunits, $\mathrm{Ca}^{2+}$ calmodulin, intracellular $\mathrm{Ca}^{2+}$, and phosphorylation by protein kinases $A$ and $C[62,63]$. Increased AC activity could result from enhanced receptor-Gs interactions and/ or by directly enhancing the activity of the enzyme [56, 57]. In guinea pig ileum longitudinal muscle myenteric plexus preparations, chronic in vivo pretreatment with morphine results in a type of cAMP overshoot wherein a reversal from inhibition to stimulation of $\mathrm{AC}$ is observed 
[59]. This chronic, in vivo pretreatment with morphine also produced an increase of the phosphorylation of ACII that is dependent on protein kinase $\mathrm{C}$ and which can significantly increase their stimulatory responsiveness to $\mathrm{G}_{\mathrm{s}} \alpha$ and $\mathrm{G} \beta \gamma$ [58]. Similarly, a CHO cell line stably transfected with the rat $\mu$-opioid receptor exhibits AC superactivation that is unaffected by cycloheximide pretreatment, indicating that no up-regulation of AC or Gas occurs in this system [55]. Others have reported that increased basal cAMP levels after sustained exposure to $\delta$ opioid receptor agonists in transfected $\mathrm{CHO}$ cells that express the human $\delta$ opioid receptors was associated with the phosphorylation of AC type VI [64]. Further, it was demonstrated that Raf-1, a key protein kinase of the MAPK signal transduction cascade that directly phosphorylates and sensitized AC VI [65], plays a role in chronic delta opioid agonist mediated AC superactivation [66].

Using cAMP superactivation as a cellular marker of opioid tolerance, it was found to be inversely related to receptor endocytosis [48]. MOR mutations that facilitated endocytosis reduced the development of cAMP superactivation, whereas MOR mutations that inhibited endocytosis increased cAMP superactivation [48]. These data suggest that opioid tolerance is likely mediated through mechanisms other than receptor endocytosis that is facilitated by beta-arrestin. A shortcoming of AC superactivation as a mechanism of opioid tolerance is that the enhanced effects of cAMP should influence the efficacy of other receptor systems whose major function is to suppress cAMP production. To date, there is little debate or attention given to testing this hypothesis further by examining possible cross-tolerance to other $\mathrm{G}_{\mathrm{i}} \alpha$-coupled receptor function after sustained opioid exposure. Moreover, whether enhanced cAMP levels are physiologically relevant in peripheral or central nociceptive neurons of opioid tolerant animals remains to be validated.

\section{Protein Kinase Activation}

Opioid exposure has been reported to activate mitogen-activated protein kinases (MAPK) in cell lines expressing the mu opioid receptor $[67,68]$, as well as activating transcription factors such as cyclic AMP-response element DNA-binding protein (CREB) in cultured DRG neurons, NG108-15 cells, and in vivo [69-72]. Within cultured DRG cells, chronic application of morphine increased phosphorylation of MAPK including p38, ERK, and JNK as well as phosphorylation of the transcription factor CREB [70]. Increased expression of phosphorylation-activated CREB (pCREB), CGRP, and SP was ob- served based on immunolabeling analysis in the dorsal root ganglion of morphine tolerant rats [70, 73]. pCREBlike immunoreactivity (-LI), CGRP-LI and SP-LI are colocalized to cultured dorsal root ganglion neurons that also express MOR. Furthermore, the MEK1 (mitogenactivated protein kinase/extracellular signal-regulated kinase kinase) inhibitor, PD98059, which blocks the MAPK pathway, inhibited morphine-induced increased expression of CGRP-LI and SP-LI, as well as phosphorylation of ERK and CREB in cultured DRG neurons [70]. Other studies have shown that ERK/MAPK activated CREB in various cell types in vitro [74] and in different brain regions in vivo [75], and that both CGRP and preprotachykinin gene promoters contain CRE [76-79]. Thus, chronic morphine exposure appears to enhance the expression of nociceptive sensory neuropeptides such as CGRP and SP via ERK/MAPK pathway and is CREB dependent.

\section{Sustained Opioid-Induced Excitatory Neurotransmission}

Another proposed mechanism for antinociceptive tolerance is that sustained opiate administration induces neuroplasticity that enhances stimulus-evoked release of excitatory neurotransmitters including glutamate, CGRP, and SP from nociceptive primary afferent fibers within the spinal cord [80-83]. An upregulation of the excitatory neurotransmitters coupled with increased stimulusevoked release of these pronociceptive neurotransmitters suggest that prolonged opiate exposure leads to sensitization of the nociceptive system. Supporting this hypothesis, opioid-induced abnormal pain has been demonstrated in several animal models after repeated spinal administration of opioids [84-86]. Moreover, rats that were made tolerant to either systemic or spinal morphine demonstrated hyper-reflexia and extreme sensitivity to handling upon the injection of either spinal or systemic naloxone [10]. Consistent with these observations, it has been interpreted that opioids given over time maintain their level of efficacy, but the concurrent development of hyperalgesia serves to counteract the antinociceptive effect of opioids, producing an impression of tolerance [87, 88]. Counter to this argument is that opioid-induced hyperalgesia is simply the result of an unmasking of a compensatory neuronal hyperactivity in response to morphine-induced inhibition of neuronal function [89]. This hyper-responsiveness, or sensitization, becomes evident either after the opioid is removed or occurs intermittently between injections such that opioid-induced hyperal- 
gesia might be interpreted as a result of repeated episodes of opioid withdrawal ('mini-withdrawals') [89]. However, both constant infusion or subcutaneous pellet implantation have been reported to produce behavioral signs of exaggerated pain [13, 81, 90, 91]. For example, the continuous spinal infusion of [D-Ala2,N-Me-Phe4,Glyol5] enkephalin (DAMGO) delivered through an osmotic minipump to rats produced antinociceptive tolerance to DAMGO or morphine, as demonstrated by a reduction in their antinociceptive effect within 6 days, and by a rightward shift in the morphine dose-response curve against the tail flick test [13]. Concurrently, these animals expressed tactile and thermal hypersensitivity, indicated by significant reductions in paw withdrawal responses to light tactile or noxious radiant heat applied to the hindpaws [13]. Importantly, these behavioral signs of abnormal pain were present while DAMGO was still being infused into the intrathecal space [13]. In a related study, the continuous exposure of rats to morphine was assured by constant infusion or the s.c. implantation of a pair of pellets containing free-base morphine [91]. Within 7 days, the rats demonstrated reduced response thresholds to light tactile or noxious radiant heat stimuli, indicating the presence of tactile and thermal hypersensitivity [91]. As with the spinal DAMGO infusion, the continuous exposure to subcutaneous morphine also produced a significant rightward shift in the spinal or systemic morphine dose-response curves [91]. These studies demonstrate that abnormal pain is present during the continuous delivery of opioids by systemic or spinal delivery, and provides evidence that the sensory changes are not due to the development of states of 'mini-withdrawals'. As pain may be thought of as a 'physiological antagonist of antinociception (or analgesia, clinically)', opioid-induced increased pain may manifest as 'opioid tolerance' $[13,83$, 90, 91].

\section{Mechanisms Mediating Opioid-Induced Pain}

\section{NMDA Receptor}

Opioid-induced pain and antinociceptive tolerance may share some underlying mechanisms with the abnormal pain occurring after peripheral nerve injury [85, 9294]. Both of these states are associated with greatly diminished antinociceptive effect of morphine and are sensitive to reversal by intrathecal NMDA antagonists, suggestive of spinal sensitization. It has long been appreciated that activation of the NMDA receptor by glutamate results in the sensitization of spinal neurons [95]. Moreover,
NMDA receptor mediated central sensitization has been associated with enhanced nociception in chronic pain states $[85,94,96]$. This observation has been extended to include opioid-induced abnormal pain [85, 97-99]. The blockade and reversal of opioid tolerance by NMDA antagonists has been repeatedly noted, indicating the importance of the NMDA receptor function in this process [86, 99-101]. In these studies, MK801 did not produce antinociception alone, nor did it increase antinociceptive action of morphine in non-tolerant rats. The development of tolerance to spinal morphine was prevented by the co-infusion of the NMDA antagonists MK801 or dextromethorphan [102]. Hyperalgesia evoked by short-term administration of heroin or fentanyl also was blocked by NMDA antagonists, as well as hyperalgesia provoked by naloxone-precipitated opiate withdrawal [87, 97, 98, 103-105]. NMDA receptors are expressed on the central terminals of primary afferent fibers $[106,107]$ as well as in spinal cord neurons. Thus NMDA receptors may promote opioid induced pain and antinociceptive tolerance presynaptically by promoting neurotransmitter output [107] and/or postsynaptic potentiation of sensory transmission.

\section{Spinal Dynorphin}

Although dynorphin was originally identified as an endogenous k-opioid agonist and may act as an endogenous antinociceptive agent under certain conditions [108110], considerable evidence indicates that enhanced expression of spinal dynorphin is pronociceptive. States of chronic inflammation and peripheral nerve injury which are accompanied by manifestations of abnormal pain, including spontaneous pain, allodynia and hyperalgesia, are also associated with elevated spinal dynorphin content [111-113]. Pain behaviors associated with nerve injury were blocked by antiserum to dynorphin $[92,114$ 117]. Dynorphin-like immunoreactivity and prodynorphin mRNA levels were elevated in the spinal cord perfusate of polyarthritic rats [118]. A single spinal injection dynorphin has produced long-lasting tactile allodynia in rats and mice $[119,120]$.

Elevations in spinal dynorphin content are also seen in condition of opioid-induced pain states [13, 121]. Spinal infusion of DAMGO over 6-7 days produced tactile and thermal hypersensitivity while the opioid infusion was continuing [13]. This treatment also produced elevated dynorphin content in the lumbar cord as well as immunoreactivity for prodynorphin [13]. The spinal injection of antiserum to dynorphin blocked these behavioral signs of abnormal pain in the DAMGO-treated rats, but 
had no effect on sensory thresholds in normal, non-tolerant rats. More importantly, antiserum to dynorphin unmasked the antinociceptive action of the still-present DAMGO [13]. There is evidence that increased spinal dynorphin promotes the further release of excitatory transmitters from primary afferent neurons, thus provoking a positive feedback loop that amplifies further sensory input. Microdialysis studies have demonstrated localized, dose-dependent release of glutamate and aspartate elicited by exogenous dynorphin in the hippocampus and spinal cord [122-124], and stimulates the production of prostaglandin E2 in the spinal cord [123]. Dynorphin also enhances the release of substance $P$ from trigeminal nuclear slices, and this effect was blocked by MK-801 but not by opioid antagonists [125]. Furthermore, capsaicinevoked release of CGRP from spinal cord tissue was potentiated by dynorphin $\mathrm{A}(2-13)$, a non-opioid fragment [81]. Importantly, dorsal spinal cord tissue taken from rats exposed to morphine pellets for 7 days demonstrated enhanced capsaicin-evoked release of CGRP, which could be blocked in the presence of dynorphin antiserum in the perfusion medium [81].

The pronociceptive actions of elevated levels of endogenous spinal dynorphin as well as enhanced activity of the NMDA receptor may therefore represent two key components in the complex pathway that gives rise to sensitization of sensory neurotransmission at the spinal cord level. Disruptions made to this pathway at the receptors (NMDA, NK-1, CGRP), or enzymes that regulate receptors, channel function, and transcription factors (MAPK, PKC), or release of neurotransmitters and modulators (EAA, neuropeptides, prostaglandins, dynorphin, calcium channels) act to disrupt both the abnormal pain states and restore antinociceptive efficacy of opiates. The overwhelming similarities in the spinal mechanisms that promote opioid induced pain and antinociceptive tolerance, while provocative, do not proof the hypothesis that opioid tolerance is a manifest of enhanced pain. More recently, we began to examine a region of the brain stem, namely the rostral ventromedial medulla (RVM), which has been established as a critical origin of descending input from the brainstem to the spinal cord to regulate pain transmission. Our findings substantiate the hypothesis that sustained opioid exposure induces plasticity in the spinal/supraspinal nociceptive transmission pathway and underlies opioid antinociceptive tolerance.

\section{Descending Modulation of Pain Transmission}

\section{Abnormal Pain Is Promoted by Descending \\ Facilitation from the RVM}

The RVM, which includes the nucleus raphe magnus and surrounding reticular neurons ventral to the nucleus gigantocellularis, has been identified as a critical region with respect to nociceptive processing and control [126128]. Numerous studies have implicated the RVM and the surrounding tissue as a prominent source of descending modulation of nociception [129-136]. Focal brain stimulation of the RVM produced a biphasic modulatory effect on nociceptive activity, with low-intensity electrical stimulation producing facilitation whereas high-intensity electrical stimulation inhibited the tail flick reflex or activity of dorsal horn units $[131,137]$. Furthermore, microinjection of the excitatory amino acid glutamate or of neurotensin into the RVM produced a similar biphasic effect, with low doses facilitating and high doses inhibiting the activity of spinal dorsal horn neurons [131, 137, 138]. Several studies have since demonstrated that nerve injury-induced hypersensitivity is dependent on descending facilitation arising from the RVM $[132,139]$. The $\mathrm{RVM}$ is generally described as consisting of 3 classes of neurons, based on response characteristics to nociceptive inputs $[126,127]$. The 'off'-cells pause in their firing immediately before a withdrawal response to nociceptive stimuli occurs. The 'on'-cells accelerate firing immediately before the nociceptive reflex occurs. The so-called 'neutral' cells show no electrophysiologic responses to nociception. Through an extensive series of experiments, it has been determined that activation of the off-cells produces an inhibition of nociceptive input and inhibition of nocifensive responses [126, 127, 140]. Conversely, the on-cells activate a descending facilitation of nociceptive processing through both local interactions within the RVM and descending systems projecting to the spinal cord $[126,127,135,136,140]$. It has been reported that spontaneous activity of on-cells increases along with facilitated pain behavior during naloxone-precipitated withdrawal [141, 142]. Thermal hyperalgesia induced by naloxone-precipitated withdrawal or prolonged delivery of a noxious thermal stimulus was blocked by administration of lidocaine into the RVM $[135,143]$. We found that the tactile and thermal hypersensitivity induced by continuous exposure to morphine by subcutaneous implant of pellets or by osmotic minipump was reversibly blocked by the microinjection of lidocaine into the RVM [91]. 


\section{The Dorsolateral Funiculus}

RVM projection neurons extend to the spinal cord via the dorsolateral funiculus (DLF). Lesion of the DLF both prevents [139] and reverses [144] nerve injury-induced pain. DLF lesion also blocks opioid-induced pain and antinociceptive tolerance to spinal opioids [91]. Rats with morphine treatment and bilateral lesions of the DLF demonstrated dose-effect curves identical to those of nontolerant rats, whereas those with sham DLF lesions and morphine pellets demonstrated a significant shift to the right of the morphine dose-response curves [91]. Normal nocifensive responses and the antinociceptive action of morphine in rats implanted with placebo pellets were not affected by DLF lesions, indicating that these changes were not due to a disruption of normal sensory processing [91]. These effects of DLF lesion are related to the changes induced in the spinal cord upon sustained opioid exposure. In fact, DLF lesion prevented the upregulation of spinal dynorphin [91] and prevented the enhanced release of CGRP from the primary afferent in spinal cord tissue slices [81]. It is important to note that, in these studies, manipulations that blocked abnormal pain did not enhance basal responses to nociception nor did they enhance the antinociceptive potencies of opioids given to non-tolerant animals. Rather, reversal of abnormal pain was specific for the tolerant state. Abolition of opioid-induced pain resulted in loss of antinociceptive tolerance, thus providing evidence that antinociceptive tolerance may reflect enhanced states of pain.

\section{Role of CCK as an Endogenous Pronociceptive (or 'Anti-Opioid') Agent}

It has been well established that CCK exists in heterogeneous distributions throughout the brain and spinal cord $[145,146]$. Notably, the distributions of CCK and of CCK receptors in the CNS show significant overlap with the distributions of endogenous opioid peptides and of opioid receptors, suggesting the possibility of complementary roles in modulation of nociception [147, 148]. Importantly, immunoreactivity for CCK is seen in periaqueductal gray (PAG), raphe nuclei and the medullary reticular formation, and nerve terminals of CCK and enkephalin-containing neurons overlap in the PAG and RVM [145, 149]. CCK immunoreactivity is predominantly associated with fibers within the RVM [150], and CCK-containing projections from the RVM to the spinal cord have been observed [151]. Under normal conditions, CCK is not found in the DRG or terminals of primary afferents of non-primates, but is detected in the superficial laminae of the spinal cord [149, 152, 153].
Spinal CCK is derived from descending projections and interneurons [145].

The spinal and supraspinal administration of CCK has produced behavioral signs of hyperalgesia and enhanced activity of dorsal horn neurons consistent with a pronociceptive role [154-156]. Spinal or systemic CCK blocked antinociception mediated by endogenous opioids and exogenous morphine [157]. CCK antagonists elicited an enhancement of morphine-induced antinociception while producing no antinociceptive activity when given alone [153, 157-162]. Furthermore, the CCKB antagonist, L365,260, inactive alone, significantly enhanced the antinociceptive effect of systemic or spinally administered morphine in rats and mice $[83,163]$. Antisense oligodeoxynucleotide 'knock-down' of the CCK2 receptor also enhances morphine antinociception [164]. Finally, antinociception mediated by endogenous opioids following blockade of enkephalinases was also enhanced by CCK antagonists [164-166]. Interestingly, CCK antagonists alone have not produced an antinociceptive effect, again indicating the lack of endogenous CCK tone in the normal condition [167].

Recently, it was found that CCK infused into the RVM blocked the antinociceptive effect of systemic morphine [168]. Although the circuitry is not fully understood, it appeared to do so by blocking the morphine-induced increase in firing of RVM off-cells [168]. Furthermore, the microinjection of CCK into the RVM of normal rats produced behavioral signs of pain demonstrated by reversible increased sensitivity to normally non-noxious mechanical stimuli and to noxious thermal stimulation [169, 170]. These results provided strong evidence that CCK is an important player in the RVM mediating descending facilitation of nociception.

There is considerable evidence that while CCK modulates the antinociceptive activity of opioids, the opioids in turn promote CCK release in the brain and the spinal cord, apparently keeping a harmonious balance between endogenous pronociceptive and antinociceptive systems [166, 167, 171-173]. Microdialysis techniques performed in vivo demonstrated that acute systemic and spinal morphine administration increased CSF levels of CCK in the spinal cord [172, 174]. Microdialysis studies also revealed a naloxone-reversible marked increase in extracellular CCK in the frontal cortex of conscious rats after acute systemic morphine administration [175]. Consistent with these observations after short-term opioid exposure, the development of antinociceptive tolerance to morphine is also associated with an upregulation of CCK within the brain and the spinal cord [171, 172, 176]. Prolonged ex- 
posure to morphine also increases CCK expression within the brain and spinal cord, which in turn further attenuates the antinociceptive effect of morphine, thus resulting in antinociceptive tolerance [172, 177, 178]. Microdialysis performed in the spinal cord of morphinetolerant rats indicated increases in $\mathrm{K}^{+}$-evoked release of CCK in vivo [179]. Moreover, sustained morphine administration correlated with persistent release of CCK in the frontal cortex [175]. Thus, sustained opioid administration increases CCK activity within the brain and spinal cord, which is known to block the antinociceptive effects of morphine and induce behavioral signs of hyperalgesia along with enhanced activity of dorsal horn neurons which is consistent with a pronociceptive role of CCK. Indeed, numerous studies have demonstrated that the coadministration of CCK antagonists with morphine prevents the development of antinociceptive tolerance [162, 180, 181]. Furthermore, behavioral signs of already established antinociceptive tolerance to morphine have been reversed by CCK antiserum or CCKB antagonists at doses that did not enhance morphine antinociception in naive rats [167, 182-184]. Thus, these studies indicate that CCK has a pivotal role in mediating antinociceptive tolerance to opioids. The mechanisms by which CCK acts as an 'antiopioid' are currently unknown. It was suggested that CCK counteracts the opioid-induced inhibition of depolarization-induced $\mathrm{Ca}^{2+}$ influx into primary afferent neurons by eliciting a mobilization of $\mathrm{Ca}^{2+}$ from intracellular stores, thus maintaining nociceptive neurotransmitter release [173]. More recent data suggest that CCK is also likely to act through the activation of pronociceptive systems arising from the RVM [185].

\section{Conclusion}

The development of tolerance to the analgesic action of opioids is well documented, and is generally considered to be an obstacle in the use of opioids for the treatment of chronic pain. Cellular adaptations such as receptor desensitization and endocytosis, adenylyl cyclase superactivation and increased cAMP levels, and activation of MAPK pathways have been proposed to explain tolerance development, possibly through changes in cytoplasmic signaling events and control of neural gene expression. Such adaptations likely lead to long-lasting changes in neural function. However, it has been difficult to link these cellular changes with systemic changes observed in response to prolonged opioid treatment. Many clinical and preclinical reports have shown that prolonged opioid administration produces paradoxical pain, requiring increased opioid dosages to induce analgesia and diminish the pain state being treated, and thus manifest behaviorally as antinociceptive tolerance. Recent evidence from our laboratories suggests that opioid-mediated paradoxical pain may be a result of neuroplastic changes at supraspinal sites that ultimately lead to the development of descending facilitation arising from the RVM. Growing evidence seems to indicate that increased facilitation arising from the RVM is likely to be mediated through increased CCK activity in this region. Descending facilitation increases expression of spinal dynorphin, which acts as an endogenous pronociceptive agent that promotes increased release of excitatory neurotransmitters from primary afferent neurons. Thus, an enhanced pain state is observed as a consequence of increased evoked release of excitatory neurotransmitters from primary afferent neurons. Based on these observations, we suggest that the combination of substances that block abnormal pain along with opioids would result in a therapeutic approach where opioid activity is maintained even over extended periods of time. Of note, the many substances shown to block opioid antinociceptive tolerance are blockers or inhibitors of endogenous substances which promote pain. 


\section{References}

$\checkmark 1$ Kalso E, et al: Opioids in chronic non-cancer pain: systematic review of efficacy and safety. Pain 2004; 112:372-380.

2 Blum RH, et al: The multidisciplinary approach to bone metastases. Oncology (Huntingt) 2003;17:845-857; discussion 862-863, 867 .

3 Cox BM: Drug tolerance and physical dependence; in Wall PD, Taylor P (eds): Principles of Drug Action: The Basis of Pharmacology. New York, Churchill-Livingstone, 1990, pp 639-690.

4 Foley KM: Opioids. Neurol Clin 1993;11:503522.

5 Foley KM: Misconceptions and controversies regarding the use of opioids in cancer pain. Anti-Cancer Drugs 1995; 6(suppl 3):4-13.

$\checkmark 6$ Way EL, Loh HH, Shen FH: Simultaneous quantitative assessment of morphine tolerance and physical dependence. J Pharmacol Exp Ther 1969;167:1-8.

7 Cherney NI, Portenoy RK: Practical issues in the management of cancer pain; in Wall PD, Melzack R (eds): Textbook of Pain. Edinburgh, Churchill-Livingstone, 1999, pp 1479-1522.

$\checkmark 8$ Fernandes M, Kluwe S, Coper H: The development of tolerance to morphine in the rat. Psychopharmacology (Berl) 1977;54:197-201.

$\checkmark 9$ Fernandes M, Kluwe S, Coper H: Quantitative assessment of tolerance to and dependence on morphine in mice. Naunyn Schmiedebergs Arch Pharmacol 1977;297:53-60.

- 10 Yaksh TL, Kohl RL, Rudy TA: Induction of tolerance and withdrawal in rats receiving morphine in the spinal subarachnoid space. Eur J Pharmacol 1977;42:275-284.

$>11$ Roerig SC, Fujimoto JM: Morphine antinociception in different strains of mice: relationship of supraspinal-spinal multiplicative interaction to tolerance. J Pharmacol Exp Ther 1988;247:603-608.

12 Roerig SC, et al: Tolerance to morphine analgesia: decreased multiplicative interaction between spinal and supraspinal sites. Brain Res 1984;308:360-363.

13 Vanderah TW, et al: Dynorphin promotes abnormal pain and spinal opioid antinociceptive tolerance. J Neurosci 2000;20:7074-7079.

14 Quock RM, et al: The delta-opioid receptor: molecular pharmacology, signal transduction, and the determination of drug efficacy. Pharmacol Rev 1999;51:503-532.

$\checkmark 15$ Connor M, Christie MJ: Opioid receptor signaling mechanisms. Clin Exp Pharmacol Physiol 1999;26:493-499.

-16 Williams JT, Christie MJ, Manzoni O: Cellular and synaptic adaptations mediating opioid dependence. Physiol Rev 2001;81:299-343.

17 Ostermeier AM, et al: Activation of mu- and delta-opioid receptors causes presynaptic inhibition of glutamatergic excitation in neocortical neurons. Anesthesiology 2000;93:10531063.
18 Yaksh TL, et al: Intrathecal morphine inhibits substance $\mathrm{P}$ release from mammalian spinal cord in vivo. Nature 1980;286:155-157.

19 Xin L, et al: Substance P release in the rat periaqueductal gray and preoptic anterior hypothalamus after noxious cold stimulation: effect of selective mu and kappa opioid agonists. J Pharmacol Exp Ther 1997;282:1055-1063.

20 Gamse R, Holzer P, Lembeck F: Indirect evidence for presynaptic location of opiate receptors on chemosensitive primary sensory neurones. Naunyn Schmiedebergs Arch Pharmacol 1979;308:281-285.

21 Abbadie C, et al: Mu and delta opioid receptor-like immunoreactivity in the cervical spinal cord of the rat after dorsal rhizotomy or neonatal capsaicin: an analysis of pre- and postsynaptic receptor distributions. Brain Res 2002;930:150-162.

22 Lamotte C, Pert CB, Snyder SH: Opiate receptor binding in primate spinal cord: distribution and changes after dorsal root section. Brain Res 1976;112:407-412.

23 Chavkin C, Goldstein A: Reduction in opiate receptor reserve in morphine tolerant guinea pig ilea. Life Sci 1982;31:1687-1690.

24 von Zastrow M: Mechanisms regulating membrane trafficking of $\mathrm{G}$ protein-coupled receptors in the endocytic pathway. Life Sci 2003; 74:217-224.

25 Ferguson SS: Evolving concepts in G proteincoupled receptor endocytosis: the role in receptor desensitization and signaling. Pharmacol Rev 2001;53:1-24.

26 Ferguson SS, et al: Role of beta-arrestins in the intracellular trafficking of G-protein-coupled receptors. Adv Pharmacol 1998;42:420-424.

27 Ferguson SS, et al: Molecular mechanisms of $\mathrm{G}$ protein-coupled receptor desensitization and resensitization. Life Sci 1998;62:15611565 .

28 Goodman CB, et al: Regulation of mu binding sites after chronic administration of antibodies directed against specific anti-opiate peptides. Peptides 1998;19:1703-1709.

29 Terman GW, et al: G-protein receptor kinase 3 (GRK3) influences opioid analgesic tolerance but not opioid withdrawal. Br J Pharmacol 2004; 141:55-64.

30 Chu P, et al: Delta and kappa opioid receptors are differentially regulated by dynamin-dependent endocytosis when activated by the same alkaloid agonist. J Biol Chem 1997;272: 27124-27130.

-31 Lefkowitz RJ: G protein-coupled receptors. III. New roles for receptor kinases and beta-arrestins in receptor signaling and desensitization. J Biol Chem 1998;273:18677-18680.

32 Lefkowitz RJ, et al: Mechanisms of beta-adrenergic receptor desensitization and resensitization. Adv Pharmacol 1998;42:416-420.

33 Przewlocka B, et al: Knockdown of spinal opioid receptors by antisense targeting beta-arrestin reduces morphine tolerance and allodynia in rat. Neurosci Lett 2002;325:107-110.
-34 Bohn LM, et al: Mu-opioid receptor desensitization by beta-arrestin-2 determines morphine tolerance but not dependence. Nature 2000; 408:720-723.

35 Bohn LM, Lefkowitz RJ, Caron MG: Differential mechanisms of morphine antinociceptive tolerance revealed in beta arrestin- 2 knock-out mice. J Neurosci 2002;22:10494-10500.

36 Bohn LM, et al: Relative opioid efficacy is determined by the complements of the G proteincoupled receptor desensitization machinery. Mol Pharmacol 2004;66:106-112.

37 Bohn LM, et al: Enhanced morphine analgesia in mice lacking beta-arrestin 2. Science 1999; 286:2495-2458.

38 Arden JR, et al: Phosphorylation and agonistspecific intracellular trafficking of an epitopetagged mu-opioid receptor expressed in HEK 293 cells. J Neurochem 1995;65:1636-1645.

39 Alvarez VA, et al: mu-Opioid receptors: liganddependent activation of potassium conductance, desensitization, and internalization. $\mathrm{J}$ Neurosci 2002;22:5769-5776.

40 von Zastrow M, et al: Regulated endocytosis of opioid receptors: cellular mechanisms and proposed roles in physiological adaptation to opiate drugs. Curr Opin Neurobiol 2003;13:348353 .

41 Keith DE, et al: Morphine activates opioid receptors without causing their rapid internalization. J Biol Chem 1996;271:19021-19024.

42 Whistler JL, et al: Functional dissociation of mu opioid receptor signaling and endocytosis: implications for the biology of opiate tolerance and addiction. Neuron 1999;23:737-746.

43 Zhang J, et al: Role for G protein-coupled receptor kinase in agonist-specific regulation of mu-opioid receptor responsiveness. Proc Natl Acad Sci USA 1998;95:7157-7162.

44 Whistler JL, von Zastrow M: Morphine-activated opioid receptors elude desensitization by beta-arrestin. Proc Natl Acad Sci USA 1998; 95:9914-9919.

45 Keith DE, et al: mu-Opioid receptor internalization: opiate drugs have differential effects on a conserved endocytic mechanism in vitro and in the mammalian brain. Mol Pharmacol 1998;53:377-384.

46 Sternini C, et al: Agonist-selective endocytosis of mu opioid receptor by neurons in vivo. Proc Natl Acad Sci USA 1996;93:9241-9246.

47 He L, et al: Regulation of opioid receptor trafficking and morphine tolerance by receptor oligomerization. Cell 2002;108:271-282.

48 Finn AK, Whistler JL: Endocytosis of the mu opioid receptor reduces tolerance and a cellular hallmark of opiate withdrawal. Neuron 2001; 32: 829-839.

49 Stevens CW, Yaksh TL: Potency of infused spinal antinociceptive agents is inversely related to magnitude of tolerance after continuous infusion. J Pharmacol Exp Ther 1989;250:1-8. 
50 Rezvani A, et al: A rapid and simple method for the quantitative determination of tolerance development to opiates in the guinea-pig ileum in vitro. J Pharmacol Exp Ther 1983;225:251255.

51 Duttaroy A, Yoburn BC: The effect of intrinsic efficacy on opioid tolerance. Anesthesiology 1995;82:1226-1236.

-52 Nestler EJ: Cellular responses to chronic treatment with drugs of abuse. Crit Rev Neurobiol 1993; 7:23-39.

$\checkmark 53$ Varga EV, et al: Molecular mechanisms of excitatory signaling upon chronic opioid agonist treatment. Life Sci 2003;74:299-311.

54 Rubenzik M, et al: Expression of alpha-transducin in Chinese hamster ovary cells stably transfected with the human delta-opioid receptor attenuates chronic opioid agonist-induced adenylyl cyclase superactivation. Mol Pharmacol 2001;60:1076-1082.

55 Avidor-Reiss T, et al: Adenylylcyclase supersensitization in mu-opioid receptor-transfected Chinese hamster ovary cells following chronic opioid treatment. J Biol Chem 1995; 270:29732-29738.

-56 Ammer H, Christ TE: Identity of adenylyl cyclase isoform determines the $\mathrm{G}$ protein mediating chronic opioid-induced adenylyl cyclase supersensitivity. J Neurochem 2002;83:818827.

57 Ammer H, Schulz R: Adenylyl cyclase supersensitivity in opioid-withdrawn NG108-15 hybrid cells requires Gs but is not mediated by the Gsalpha subunit. J Pharmacol Exp Ther 1998;286:855-862.

-58 Chakrabarti S, et al: Chronic morphine augments adenylyl cyclase phosphorylation: relevance to altered signaling during tolerance/dependence. Mol Pharmacol 1998;54:949-953.

$\checkmark 59$ Chakrabarti S, et al: Chronic morphine augments $\mathrm{G}$ (beta)(gamma)/Gs(alpha) stimulation of adenylyl cyclase: relevance to opioid tolerance. Mol Pharmacol 1998;54:655-662.

60 Alves ID, et al: Selectivity, cooperativity, and reciprocity in the interactions between the $\{\mathrm{del}-$ ta\}-opioid receptor, its ligands, and G-proteins. J Biol Chem 2004;279:44673-44682.

61 Crain SM, Shen K-F: Antagonists of excitatory opioid receptor functions enhance morphine's analgesic potency and attenuate opioid tolerance/dependence liability. Pain 2000;84:121131.

-62 Sunahara RK, Dessauer CW, Gilman AG: Complexity and diversity of mammalian adenylyl cyclases. Annu Rev Pharmacol Toxicol 1996;36:461-480.

63 Taussig R, Gilman AG: Mammalian membrane-bound adenylyl cyclases. J Biol Chem 1995;270:1-4.

-64 Varga EV, et al: Phosphorylation of adenylyl cyclase VI upon chronic delta-opioid receptor stimulation. Eur J Pharmacol 1999;364:R1R3.

65 Tan CM, et al: Tyrosine kinase-mediated serine phosphorylation of adenylyl cyclase. Biochemistry 2001;40:1702-1709.
66 Varga EV, et al: Converging protein kinase pathways mediate adenylyl cyclase superactivation upon chronic \{delta\}-opioid agonist treatment. J Pharmacol Exp Ther 2003;306: 109-115.

67 Chuang LF, Killam KF Jr, Chuang RY: Induction and activation of mitogen-activated protein kinases of human lymphocytes as one of the signaling pathways of the immunomodulatory effects of morphine sulfate. J Biol Chem 1997;272:26815-26817.

68 Li LY, Chang KJ: The stimulatory effect of opioids on mitogen-activated protein kinase in Chinese hamster ovary cells transfected to express mu-opioid receptors. Mol Pharmacol 1996:50:599-602.

69 Li X, Clark JD: Morphine tolerance and transcription factor expression in mouse spinal cord tissue. Neurosci Lett 1999;272:79-82.

$70 \mathrm{Ma} \mathrm{W}$, et al: Chronic morphine exposure increases the phosphorylation of MAP kinases and the transcription factor CREB in dorsal root ganglion neurons: an in vitro and in vivo study. Eur J Neurosci 2001;14:1091-1104.

71 Guitart X, et al: Regulation of cyclic AMP response element-binding protein (CREB) phosphorylation by acute and chronic morphine in the rat locus coeruleus. J Neurochem 1992;58: 1168-1171.

72 Bilecki W, Hollt V, Przewlocki R: Acute deltaopioid receptor activation induces CREB phosphorylation in NG108-15 cells. Eur J Pharmacol 2000;390:1-6.

73 Powell KJ, Quirion R, Jhamandas K: Inhibition of neurokinin-1-substance\&nbsp. P receptor and prostanoid activity prevents and reverses the development of morphine tolerance in vivo and the morphine-induced increase in CGRP expression in cultured dorsal root ganglion neurons. Eur J Neurosci 2003; 18:1572_ 1583 .

74 Caivano M, Cohen P: Role of mitogen-activated protein kinase cascades in mediating lipopolysaccharide-stimulated induction of cyclooxygenase-2 and IL-1 beta in RAW264 macrophages. J Immunol 2000; 164:30183025 .

75 Davis S, et al: The MAPK/ERK cascade targets both Elk-1 and cAMP response element-binding protein to control long-term potentiationdependent gene expression in the dentate gyrus in vivo. J Neurosci 2000;20:4563-4572.

76 Freeland K, Liu YZ, Latchman DS: Distinct signalling pathways mediate the cAMP response element (CRE)-dependent activation of the calcitonin gene-related peptide gene promoter by cAMP and nerve growth factor. Biochem J 2000;345:233-238.

77 Watson A, et al: A minimal CGRP gene promoter is inducible by nerve growth factor in adult rat dorsal root ganglion neurons but not in PC12 phaeochromocytoma cells. Eur J Neurosci 1995; 7:394-400.
78 Watson A, Latchman D: The cyclic AMP response element in the calcitonin/calcitonin gene-related peptide gene promoter is necessary but not sufficient for its activation by nerve growth factor. J Biol Chem 1995;270: 9655-9660.

79 Qian J, et al: Cloning of human preprotachykinin-I promoter and the role of cyclic adenosine $5 '$-monophosphate response elements in its expression by IL-1 and stem cell factor. J Immunol 2001;166:2553-2561.

80 Jhamandas K, et al: Spinal amino acid release and precipitated withdrawal in rats chronically infused with spinal morphine. $\mathrm{J}$ Neurosci 1996; 16:2758-2766.

81 Gardell LR, et al: Sustained morphine exposure induces a spinal dynorphin-dependent enhancement of excitatory transmitter release from primary afferent fibers. J Neurosci 2002 ; 22:6747-6755.

82 Trang T, et al: The role of spinal neuropeptides and prostaglandins in opioid physical dependence. Br J Pharmacol 2002;136:37-48.

83 Ossipov $\mathrm{MH}$, et al: Induction of pain facilitation by sustained opioid exposure: relationship to opioid antinociceptive tolerance. Life Sci 2003; 73:783-800.

84 Yaksh TL, Harty GJ: Pharmacology of the allodynia in rats evoked by high dose intrathecal morphine. J Pharmacol Exp Ther 1988;244: 501-507.

85 Mao J, Price DD, Mayer DJ: Mechanisms of hyperalgesia and morphine tolerance: a current view of their possible interactions. Pain 1995; 62:259-274.

86 Trujillo KA, Akil H: Inhibition of morphine tolerance and dependence by the NMDA receptor antagonist MK-801. Science 1991;251: 85-87.

87 Laulin JP, et al: Opiate tolerance to daily heroin administration: an apparent phenomenon associated with enhanced pain sensitivity. Neuroscience 1999;89:631-636.

88 Colpaert FC: System theory of pain and of opiate analgesia: no tolerance to opiates. Pharmacol Rev 1996;48:355-402.

89 Gutstein HB: The effects of pain on opioid tolerance: how do we resolve the controversy? Pharmacol Rev 1996;48:403-407; discussion 409-411.

90 Vanderah TW, et al: Mechanisms of opioidinduced pain and antinociceptive tolerance: descending facilitation and spinal dynorphin. Pain 2001;92:5-9.

-91 Vanderah TW, et al: Tonic descending facilitation from the rostral ventromedial medulla mediates opioid-induced abnormal pain and antinociceptive tolerance. J Neurosci 2001;21: 279-286.

92 Bian D, et al: Loss of antiallodynic and antinociceptive spinal/supraspinal morphine synergy in nerve-injured rats: restoration by MK-801 or dynorphin antiserum. Brain Res 1999;831: 55-63. 
$>93$ Mao J, Price DD, Mayer DJ: Experimental mononeuropathy reduces the antinociceptive effects of morphine: implications for common intracellular mechanisms involved in morphine tolerance and neuropathic pain. Pain 1995;61:353-364.

$>94$ Wegert S, et al: Differential activities of intrathecal MK-801 or morphine to alter responses to thermal and mechanical stimuli in normal or nerve-injured rats. Pain 1997;71: 57-64.

-95 Baranauskas G, Nistri A: Sensitization of pain pathways in the spinal cord: cellular mechanisms. Prog Neurobiol 1998;54:349_ 365.

$>96$ Haley JE, Wilcox GL, Chapman PF: The role of nitric oxide in hippocampal long-term potentiation. Neuron 1992;8:211-216.

$\checkmark 97$ Larcher A, et al: Acute tolerance associated with a single opiate administration: involvement of N-methyl- $D$-aspartate-dependent pain facilitatory systems. Neuroscience 1998; 84:583-589.

$\checkmark 98$ Celerier E, et al: Long-lasting hyperalgesia induced by fentanyl in rats: preventive effect of ketamine. Anesthesiology 2000;92:465-472.

$>99$ Mao J, Price DD, Mayer DJ: Thermal hyperalgesia in association with the development of morphine tolerance in rats: roles of excitatory amino acid receptors and protein kinase C. J Neurosci 1994; 14:2301-2312.

100 Tiseo PJ, et al: Modulation of morphine tolerance by the competitive N-methyl- $D$-aspartate receptor antagonist LY274614: assessment of opioid receptor changes. J Pharmacol Exp Ther 1994;268:195-201.

101 Tiseo PJ, Inturrisi CE: Attenuation and reversal of morphine tolerance by the competitive N-methyl- $D$-aspartate receptor antagonist, LY274614. J Pharmacol Exp Ther 1993; 264:1090-1096.

102 Manning BH, et al: Continuous co-administration of dextromethorphan or MK-801 with morphine: attenuation of morphine dependence and naloxone-reversible attenuation of morphine tolerance. Pain 1996;67:79-88.

103 Celerier E, et al: Evidence for opiate-activated NMDA processes masking opiate analgesia in rats. Brain Res 1999;847:18-25.

104 Laulin JP, et al: Long-lasting increased pain sensitivity in rat following exposure to heroin for the first time. Eur J Neurosci 1998;10: 782-785.

105 Celerier E, et al: Progressive enhancement of delayed hyperalgesia induced by repeated heroin administration: a sensitization process. J Neurosci 2001;21:4074-4080.

106 Liu H, et al: Evidence for presynaptic Nmethyl- $D$-aspartate autoreceptors in the spinal cord dorsal horn. Proc Natl Acad Sci USA 1994;91:8383-8387.

107 Liu H, Mantyh PW, Basbaum AI: NMDAreceptor regulation of substance $\mathrm{P}$ release from primary afferent nociceptors. Nature 1997;386:721-724.

108 Akil H, et al: Endogenous opioids: biology and function. Annu Rev Neurosci 1984;7: 223-255.
109 Ossipov MH, et al: Naltrindole, an opioid delta antagonist, blocks the enhancement of morphine-antinociception induced by a CCKB antagonist in the rat. Neurosci Lett 1994;181:9-12.

110 Goldstein A, et al: Dynorphin-(1-13), an extraordinarily potent opioid peptide. Proc Natl Acad Sci USA 1979;76:6666-6670.

111 Dubner R, Ruda MA: Activity-dependent neuronal plasticity following tissue injury and inflammation. Trends Neurosci 1992;15:96103.

112 Draisci G, et al: Up-regulation of opioid gene expression in spinal cord evoked by experimental nerve injuries and inflammation. Brain Res 1991;560:186-192.

113 Kajander KC, et al: Dynorphin increases in the dorsal spinal cord in rats with a painful peripheral neuropathy. Peptides 1990;11: 719-728.

114 Wagner R, Deleo JA: Pre-emptive dynorphin and N-methyl- $D$-aspartate glutamate receptor antagonism alters spinal immunocytochemistry but not allodynia following complete peripheral nerve injury. Neuroscience 1996;72:527-534.

115 Wagner R, et al: Spinal dynorphin immunoreactivity increases bilaterally in a neuropathic pain model. Brain Res 1993;629:323-326.

116 Malan TP, et al: Extraterritorial neuropathic pain correlates with multisegmental elevation of spinal dynorphin in nerve-injured rats. Pain 2000;86:185-194.

117 Wang Z, et al: Pronociceptive actions of dynorphin maintain chronic neuropathic pain. J Neurosci 2001;21:1779-1786.

118 Pohl M, et al: Enkephalinergic and dynorphinergic neurons in the spinal cord and dorsal root ganglia of the polyarthritic rat - in vivo release and cDNA hybridization studies. Brain Res 1997;749:18-28.

119 Laughlin TM, et al: Spinally administered dynorphin A produces long-lasting allodynia: involvement of NMDA but not opioid receptors. Pain 1997;72:253-260.

120 Vanderah TW, et al: Single intrathecal injections of dynorphin A or des-Tyr-dynorphins produce long-lasting allodynia in rats: blockade by MK-801 but not naloxone. Pain 1996; 68:275-281.

121 Gardell LR, et al: Pronociceptive effects of spinal dynorphin promote cannabinoid-induced pain and antinociceptive tolerance. Pain 2002;98:79-88.

122 Skilling SR, et al: Selective potentiation of NMDA-induced activity and release of excitatory amino acids by dynorphin: possible roles in paralysis and neurotoxicity. Brain Res 1992;575:272-278.

123 Koetzner L, et al: Nonopioid actions of intrathecal dynorphin evoke spinal excitatory amino acid and prostaglandin E2 release mediated by cyclooxygenase-1 and -2 . J. Neurosci 2004;24:1451-1458.

124 Faden AI: Dynorphin increases extracellular levels of excitatory amino acids in the brain through a non-opioid mechanism. J Neurosci 1992; 12:425-429.
125 Arcaya JL, et al: Dynorphin A increases substance $\mathrm{P}$ release from trigeminal primary afferent C-fibers. Eur J Pharmacol 1999;366: 27-34.

126 Fields HL, Heinricher MM: Anatomy and physiology of a nociceptive modulatory system. Philos Trans R Soc Lond [B] 1985;308: 361-374.

127 Fields HL, et al: The activity of neurons in the rostral medulla of the rat during withdrawal from noxious heat. J Neurosci 1983; 3:2545-2552.

128 Fields HL, et al: Evidence that disinhibition of brain stem neurones contributes to morphine analgesia. Nature 1983;306:684-686.

129 Calejesan AA, Kim SJ, Zhuo M: Descending facilitatory modulation of a behavioral nociceptive response by stimulation in the adult rat anterior cingulate cortex. Eur J Pain 2000; 4:83-96.

130 Zhuo M, Gebhart GF: Biphasic modulation of spinal nociceptive transmission from the medullary raphe nuclei in the rat. J Neurophysiol 1997;78:746-758.

131 Zhuo M, Gebhart GF: Characterization of descending facilitation and inhibition of spinal nociceptive transmission from the nuclei reticularis gigantocellularis and gigantocellularis pars alpha in the rat. J Neurophysiol 1992;67:1599-1614.

132 Urban MO, Gebhart GF: Supraspinal contributions to hyperalgesia. Proc Natl Acad Sci USA 1999;96:7687-7692.

133 Urban MO, Gebhart GF: Central mechanisms in pain. Med Clin N Am 1999;83:585596.

134 McNally GP: Pain facilitatory circuits in the mammalian central nervous system: their behavioral significance and role in morphine analgesic tolerance. Neurosci Biobehav Rev 1999;23:1059-1078.

135 Kaplan H, Fields HL: Hyperalgesia during acute opioid abstinence: evidence for a nociceptive facilitating function of the rostral ventromedial medulla. J Neurosci 1991;11: 1433-1439.

136 Heinricher MM, Roychowdhury SM: Reflexrelated activation of putative pain facilitating neurons in rostral ventromedial medulla requires excitatory amino acid transmission. Neuroscience 1997;78:1159-1165.

137 Zhuo M, Gebhart GF: Characterization of descending inhibition and facilitation from the nuclei reticularis gigantocellularis and gigantocellularis pars alpha in the rat. Pain 1990;42:337-350.

138 Urban MO, Gebhart GF: Characterization of biphasic modulation of spinal nociceptive transmission by neurotensin in the rat rostral ventromedial medulla. J Neurophysiol 1997; 78:1550-1562.

139 Porreca F, Ossipov MH, Gebhart GF: Chronic pain and medullary descending facilitation. Trends Neurosci 2002;25:319-325.

140 Heinricher MM, Morgan MM, Fields HL: Direct and indirect actions of morphine on medullary neurons that modulate nociception. Neuroscience 1992;48:533-543. 
$>141$ Kim DH, Fields HL, Barbaro NM: Morphine analgesia and acute physical dependence: rapid onset of two opposing, dose-related processes. Brain Res 1990;516:37-40.

142 Bederson JB, Fields HL, Barbaro NM: Hyperalgesia during naloxone-precipitated withdrawal from morphine is associated with increased on-cell activity in the rostral ventromedial medulla. Somatosens Mot Res 1990; 7:185-203.

-143 Morgan MM, Fields HL: Pronounced changes in the activity of nociceptive modulatory neurons in the rostral ventromedial medulla in response to prolonged thermal noxious stimuli. J Neurophysiol 1994; 72: 1161-1170.

144 Burgess SE, Gardell LR, Ossipov MH, Malan TP Jr, Vanderah TW, Lai J, Porreca F: Timedependent descending facilitation from the rostral ventromedial medulla maintains, but does not initiate, neuropathic pain. J Neurosci 2002;22:5129-5136.

145 Baber NS, Dourish CT, Hill DR: The role of CCK caerulein, and CCK antagonists in nociception. Pain 1989;39:307-328.

146 Savasta M, Palacios JM, Mengod G: Regional localization of the mRNA coding for the neuropeptide cholecystokinin in the rat brain studied by in situ hybridization. Neurosci Lett 1988;93:132-138.

147 Stengaard-Pedersen K, Larsson LI: Localization and opiate receptor binding of enkephalin, CCK and ACTH/beta-endorphin in the rat central nervous system. Peptides 1981; 2(suppl 1):3-19.

148 Ghilardi JR, et al: Trigeminal and dorsal root ganglion neurons express CCK receptor binding sites in the rat, rabbit, and monkey: possible site of opiate-CCK analgesic interactions. J Neurosci 1992;12:4854-4866.

149 Hokfelt T, et al: Immunohistochemical studies on cholecystokinin (CCK)-immunoreactive neurons in the rat using sequence specific antisera and with special reference to the caudate nucleus and primary sensory neurons. J Chem Neuroanat 1988;1:11-51.

-150 Skinner K, Basbaum AI, Fields HL: Cholecystokinin and enkephalin in brain stem pain modulating circuits. Neuroreport 1997;8: 2995-2998.

-151 Mantyh PW, Hunt SP: Evidence for cholecystokinin-like immunoreactive neurons in the rat medulla oblongata which project to the spinal cord. Brain Res 1984;291:49-54.

152 Verge VM, Wiesenfeld-Hallin Z, Hokfelt T: Cholecystokinin in mammalian primary sensory neurons and spinal cord: in situ hybridization studies in rat and monkey. Eur J Neurosci 1993;5:240-250.

153 Stanfa LC, Dickenson AH: Cholecystokinin as a factor in the enhanced potency of spinal morphine following carrageenin inflammation. Br J Pharmacol 1993;108:967-973.

154 Hong EK, Takemori AE: Indirect involvement of delta opioid receptors in cholecystokinin octapeptide-induced analgesia in mice. J Pharmacol Exp Ther 1989;251:594-598.
155 Jeftinija S, Miletic V, Randic M: Cholecystokinin octapeptide excites dorsal horn neurons both in vivo and in vitro. Brain Res 1981;213: 231-236.

156 Pittaway KM, et al: CCK 8 analgesia and hyperalgesia after intrathecal administration in the rat: comparison with CCK-related peptides. Neuropeptides 1987;10:87-108.

157 Faris PL: Opiate antagonistic function of cholecystokinin in analgesia and energy balance systems. Ann NY Acad Sci 1985;448:437447.

158 Hughes J, Hunter JC, Woodruff GN: Neurochemical actions of CCK underlying the therapeutic potential of CCK-B antagonists. Neuropeptides 1991;19(suppl):85-89.

159 Suh HH, Tseng LF: Differential effects of sulfated cholecystokinin octapeptide and proglumide injected intrathecally on antinociception induced by beta-endorphin and morphine administered intracerebroventricularly in mice. Eur J Pharmacol 1990;179:329-338.

160 Watkins LR, et al: Cholecystokinin antagonists selectively potentiate analgesia induced by endogenous opiates. Brain Res 1985;327: 181-190.

161 Watkins LR, Kinscheck IB, Mayer DJ: Potentiation of morphine analgesia by the cholecystokinin antagonist proglumide. Brain Res 1985;327:169-180.

162 Dourish CT, Hawley D, Iversen SD: Enhancement of morphine analgesia and prevention of morphine tolerance in the rat by the cholecystokinin antagonist L-364,718. Eur J Pharmacol 1988; 147:469-472.

163 Vanderah TW, et al: Enhancement of morphine antinociception by a CCKB antagonist in mice is mediated via opioid delta receptors. J Pharmacol Exp Ther 1996;278:212219.

164 Vanderah TW, et al: Antisense oligodeoxynucleotide to the CCKB receptor produces naltrindole- and [Leu5]enkephalin antiserum-sensitive enhancement of morphine antinociception. Neuroreport 1994;5:26012605.

165 Maldonado R, et al: Association of the peptidase inhibitor RB 101 and a CCK-B antagonist strongly enhances antinociceptive responses. Neuroreport 1993;4:947-950.

166 Noble F, Derrien M, Roques BP: Modulation of opioid antinociception by CCK at the supraspinal level: evidence of regulatory mechanisms between CCK and enkephalin systems in the control of pain. Br J Pharmacol 1993;109:1064-1070.

167 Wiesenfeld-Hallin Z, Xu X-J: The role of cholecystokinin in nociception, neuropathic pain and opiate tolerance. Regul Pept 1996;65: 23-28.

168 Heinricher MM, McGaraughty S, Tortorici V: Circuitry underlying antiopioid actions of cholecystokinin within the rostral ventromedial medulla. J Neurophysiol 2001;85:280-286.

169 Kovelowski CJ, et al: Supraspinal cholecystokinin may drive tonic descending facilitation mechanisms to maintain neuropathic pain in the rat. Pain 2000;87:265-273.
170 Xie JY, et al: Cholecystokinin in the rostral ventromedial medulla mediates opioid-induced hyperalgesia and antinociceptive tolerance. J Neurosci 2005;25:409-416.

171 Zhou Y, et al: Accelerated expression of cholecystokinin gene in the brain of rats rendered tolerant to morphine. Neuroreport 1992;3: 1121-1123.

172 Zhou Y, et al: Increased release of immunoreactive cholecystokinin octapeptide by morphine and potentiation of mu-opioid analgesia by CCKB receptor antagonist L-365,260 in rat spinal cord. Eur J Pharmacol 1993;234: 147-154.

173 Stanfa L, et al: Cholecystokinin and morphine analgesia: variations on a theme. Trends Pharmacol Sci 1994;15:65-66.

174 de Araujo Lucas G, et al: Differential release of cholecystokinin by morphine in rat spinal cord. Neurosci Lett 1998;245:13-16.

175 Becker C, et al: Delta(2)-opioid receptor mediation of morphine-induced CCK release in the frontal cortex of the freely moving rat. Synapse 1999;34:47-54.

176 Ding XZ, Bayer BM: Increases of CCK mRNA and peptide in different brain areas following acute and chronic administration of morphine. Brain Res 1993;625:139-144.

$177 \mathrm{Pu} \mathrm{S}$, et al: Cholecystokinin gene expression in rat amygdaloid neurons: normal distribution and effect of morphine tolerance. Brain Res Mol Brain Res 1994;21:183-189.

$178 \mathrm{Pu} \mathrm{SF}$, Zhuang HX, Han JS: Cholecystokinin octapeptide (CCK-8) antagonizes morphine analgesia in nucleus accumbens of the rat via the CCK-B receptor. Brain Res 1994;657: 159-164.

179 Lucas GA, et al: Extracellular cholecystokinin levels in the rat spinal cord following chronic morphine exposure: an in vivo microdialysis study. Brain Res 1999;821:79-86.

180 Kellstein DE, Mayer DJ: Spinal co-administration of cholecystokinin antagonists with morphine prevents the development of opioid tolerance. Pain 1991;47:221-229.

$181 \mathrm{Xu}$ XJ, et al: CI988, a selective antagonist of cholecystokinin $\mathrm{B}$ receptors, prevents morphine tolerance in the rat. $\mathrm{Br} \mathrm{J}$ Pharmacol 1992; 105:591-596.

182 Ding XZ, et al: Reversal of tolerance to morphine but no potentiation of morphine-induced analgesia by antiserum against cholecystokinin octapeptide. Neuropharmacology 1986;25:1155-1160.

183 Hoffmann O, Wiesenfeld-Hallin Z: The CCK-B receptor antagonist $\mathrm{Cl} 988$ reverses tolerance to morphine in rats. Neuroreport 1994;5:2565-2568.

184 Singh L, et al: Effect of CCK receptor antagonists on the antinociceptive, reinforcing and gut motility properties of morphine. $\mathrm{Br} \mathrm{J}$ Pharmacol 1996;118:1317-1325.

185 Heinricher MM, Neubert MJ: Neural basis for the hyperalgesic action of cholecystokinin in the rostral ventromedial medulla. J Neurophysiol 2004;1009:223-227. 